\title{
Catalytic State of Exogenous Enzymes in the Processing of Cotton Seeds
}

\author{
Abbos Khasanov ${ }^{1}$, Muzzaffar Ataev ${ }^{1}$, Kakhramon Davranov $^{2}$ and Khasan Khasanov ${ }^{1}$ \\ 1. Department of Technology of Food Products, Tashkent Institute of Chemical Technology, Tashkent 100011, Uzbekistan \\ 2. Department of Biotechnology, National University of Uzbekistan, Tashkent 100095, Uzbekistan
}

\begin{abstract}
The effect of gossypol, linolenic acid and cottonseed oil on the activity and stability of acidic (Aspergillus niger) and neutral (Bacillus amyloliquefaciens) proteinases was studied. Fatty acids and gossypol negatively affect the activity and stability of enzymes. The inhibitory effect of fatty acids and gossypol is most pronounced in the case of neutral proteinases. This also decreases the affinity of the enzyme to the substrate. The heat treatment of cottonseed kernels has a positive effect on enzymatic processes and facilitates the process of oil extraction.
\end{abstract}

Key words: Cottonseed kernels, proteins, carbohydrates, hydrolysis, proteinase, amylase, gossypol, fatty acid, influence, activity and stability.

\section{Introduction}

Cotton seed (cotton) is one of the most important oilseeds in Uzbekistan. The main product of cottonseed processing is refined cottonseed oil. A by-product of the oil extraction process is a cottonseed meal that has a relatively high protein content of $35-40 \%$, which makes it an attractive and promising source of vegetable proteins. Nevertheless, the presence of anti-nutrients is one of the main disadvantages in using it as human food. Consequently, it is generally used as a feed for animals.

Recently, enzymes have become widely used in the processing of oilseeds. Enzymes are used both at the stage of oilseed processing [1, 2], and at the stage of refining and modification of oils [3-6].

Removing oil with enzymes from the aquatic environment is an alternative technology for extracting oil from oil seeds. In this case, the enzymes used must hydrolyze the high-molecular compounds that impede the extraction process. After fermentation,

Corresponding author: Khasan Khasanov, assistant professor, research fields: food biotechnology and enzyme engineering. the oil must be easily separated from the aqueous medium [7].

This method was used to extract oil from soybean seeds $[8,9]$, sunflower seeds [10], rice bran [11], corn $[12,13]$, and rape [14].

The water-fermentation oil extraction that has appeared in the oil of the fat industry has several advantages over the traditional method [7]. This excludes the process of hydration and extraction of oils using organic solvents $[15,16]$.

Carbohydrase, in the composition with other enzymes, was used to treat oil seeds during expel pressing. Enzyme treatment contributed to an increase in oil yield to $90-92 \%$ [17]. Without fermentation, the yield was $72-78 \%$. At the same time, the capacity of equipment increased by $51 \%$ and oil flow by $84 \%$.

The possibility of using enzymes in the extraction of oil from soybean and sunflower seeds was studied by Dominguez with coauthors [18]. It was shown that the particle size, moisture content, enzyme concentration and fermentation time play an important role in the oil recovery process. Reducing the particle size from $2 \mathrm{~mm}$ to $1 \mathrm{~mm}$ contributed to increasing in oil yield by $35 \%$ for soybean and $50 \%$ for sunflower. 
During the enzyme treatment, the required moisture content was $50 \%$ for soybean and $20-30 \%$ for sunflower. Higher enzyme concentration of up to 1 $\mathrm{g} / 100 \mathrm{~g}$ for soybean and $2 \mathrm{~g} / 100 \mathrm{~g}$ for sunflower, increased the yield of the oil. For both seeds, the optimal fermentation time was $6 \mathrm{~h}$.

Enzymatic treatment of oil-bearing crops has a positive effect on the extraction of oils. It was shown that the use of carbohydrases allows increasing the yield of oil and reducing the time of extraction of oils [19]. For this, oil seeds were moistened to $30 \%, 0.12 \%$ enzyme was added and incubated for 12 hours at $50{ }^{\circ} \mathrm{C}$. Then, the raw material moisture was reduced to $4 \%$ and the oil was is extracted with hexane. In this case, the use of enzyme with mixed activities (proteases, amylases) gives the best results as compared to enzymes when used alone.

When fermenting oilseeds, the choice of enzymes for the fermentation of raw materials and the conditions for the process is important. Depending on the composition of the structural components of oil seeds, enzymes with the desired catalytic properties should be chosen.

It should also be noted that big amount of various compounds proteins, lipids, polysaccharides, phosphatides, colorants and their complexes in the grains of oil-bearing crops can affect the activity and stability of the enzymes used. Therefore, it is necessary to study the activity and stability of enzymes in conditions close to natural.

The multicomponent nature of essential substrates leads to the fact that the enzymes used, lose their activity due to interaction with various components of the processed raw materials. Such compounds include gossypol, fatty acids, phenolic substances, surface-active substances, products forming during the heat treatment of raw materials, etc.

The aim of this work is to study the influence of cotton seed components on the catalytic properties of enzymes and on the extraction of oil.

\section{Materials and Methods}

We used sour proteinase from the fungus Aspergillus niger (Prolive PAC $30 \quad$ L "Enzymbioprodukt" LLC, Russia), neutral bacterial proteinase from bacteria-Bacillus amyloliquefaciens (Neutraza, "Novozymes", Denmark), $\alpha$-amylase (Amilek 3T, "Expo Tech” Ltd., Russia) and $\beta$-amylase (Diazim X4, Expo Tech Ltd., Russia).

Gossypol was provided by the Institute of Bioorganic Chemistry, Academy of Sciences of Uzbekistan.

\subsection{Measurement of Proteolytic Activity}

The proteolytic activity was estimated by using the modified method of Anson, using albumin and globulin isolated from defatted cottonseed kernels as a substrate [20].

\subsection{Measurement of Enzymes Thermal Stability}

Thermostability of the enzyme was studied in the incubation medium heated to $50{ }^{\circ} \mathrm{C}$ in $0.1 \mathrm{M}$ universal buffer (at the required $\mathrm{pH}$ of the medium). In some cases, the incubation medium contained $8 \mathrm{mg} / \mathrm{mL}$ of cottonseed oil, linolenic acid and $1 \mathrm{mg} / \mathrm{mL}$ of gossypol. After certain time of incubation, $0.5 \mathrm{~mL}$ samples was taken and the enzyme activity was measured.

The enzyme activity was measured at $30{ }^{\circ} \mathrm{C}$, in a medium containing $1 \%$ albumin solution with activity 0.027-0.030 U/mL.

\subsection{Enzymatic Processing of Cottonseed Kernels}

Totally, $250 \mathrm{~g}$ of cottonseed kernels was sprayed with $5 \mathrm{~mL}$ of an enzymatic solution consisting of a mixture of $\alpha$-amylase, $\beta$-amylase, and acidic or neutral proteinase $(0.1 \%$ by weight of cottonseed kernels). After mixing, the kernel was kept in a dry-air thermostat at $50{ }^{\circ} \mathrm{C}$ for 1 hour. Then the temperature of the mass raised to $110{ }^{\circ} \mathrm{C}$ and held for $20-30$ minutes, after that the oil was extracted by pressing. Oil content of the cake was determined on a Soxhlet device [21]. 


\subsection{Determination of Protein Hydrolysis Products in} Fermented Cottonseed Kernels

The $15 \%$ solution of fermented cottonseed kernels in water was prepared and mixed with a magnetic stirrer for 5 minutes, then filtered through a filter paper, $2 \mathrm{~mL}$ of sample was taken, $2 \mathrm{~mL}$ of TCA (trichloroacetic acid) was added to inactivate the enzyme. Then the pooled solution was filtered through a filter paper, $1 \mathrm{~mL}$ of the filtrate was taken and, $5 \mathrm{~mL}$ of $0.5 \mathrm{M}$ sodium carbonate solution was added. While stirring, $1 \mathrm{~mL}$ of Folin's solution was added. The remaining operations were performed according to the method described [20].

\subsection{Determination of Carbohydrate Hydrolysis} Products in Fermented Cottonseed Kernels

The determination of reducing sugars content in the filtrates obtained from a $15 \%$ solution of fermented cottonseed kernels was carried out according to the method of Nelson and Shomodi [22].

\section{Results and Discussion}

Enzymes in solutions undergo denaturation under the influence of various factors. Many compounds (detergents, organic solvents, fatty acids, lipids, phenols, gossypol, etc.) are able to inactivate enzymes. These processes accelerated with increasing temperature. Therefore, when developing the ways to use them to solve practical problems, the information on the mechanisms of inactivation of a particular type of enzyme in different conditions is necessary.

3.1 The Effect of Lipids and Fatty Acids on the Activity and Stability of Proteinases

In aqueous media, the enzymes Neutraza (neutral proteinase) and Prolive-RAS (acidic proteinase) are fairly stable. In Fig. 1 the thermal stability of acid and neutral proteinases at different temperatures is shown.

From the data presented, it is seen that at $45{ }^{\circ} \mathrm{C}$ both enzymes are stable but after 90 min incubation the enzyme activity decreased by $6-7 \%$ in case of acidic proteinase and $20 \%$ in case of neutral proteinase (Fig. 1, curves 1). The increase of temperature led to acceleration of the inactivation process and at $50{ }^{\circ} \mathrm{C}$ after $90 \mathrm{~min}$ incubation the decrease in activity after $90 \mathrm{~min}$ incubation was 27 and $43 \%$, respectively. Increasing the temperature up to $55{ }^{\circ} \mathrm{C}$ led to a sharp increase in the rate of inactivation of neutral proteinase and the residual activity after 90 min of incubation was just $15 \%$. At the same conditions, acidic proteinase lost only $52 \%$ of the initial activity.

Thus, it has been established that acidic proteinase has a higher thermostability than neutral proteinase.

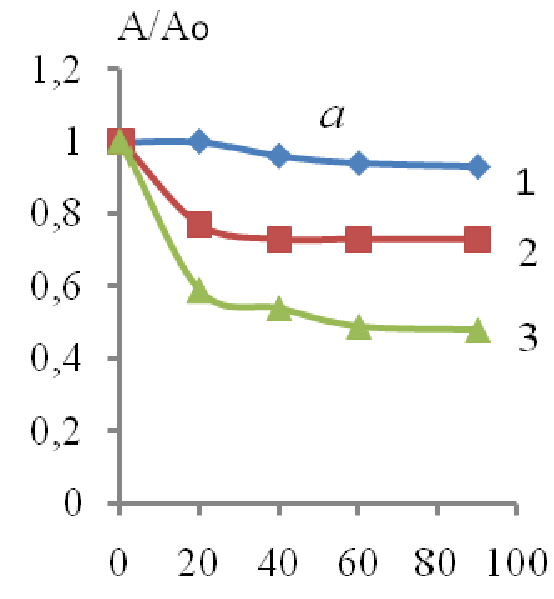

Time, in min

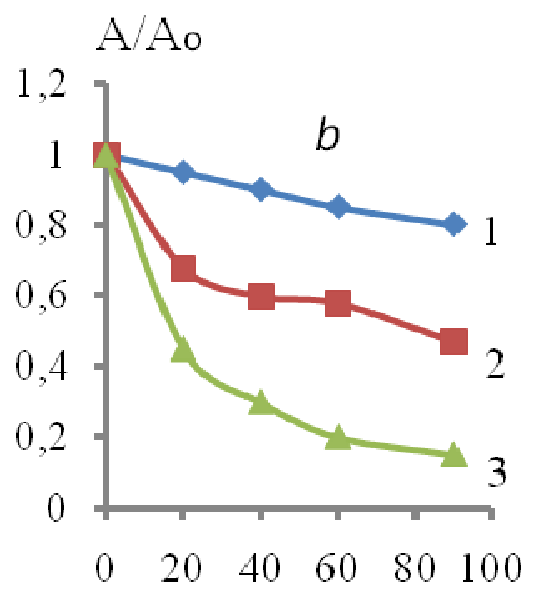

Time, in min

Fig. 1 The stability of acid (a) and neutral (b) proteinases at different temperatures: $1-45{ }^{\circ} \mathrm{C}, 2-50{ }^{\circ} \mathrm{C}, 3-55^{\circ} \mathrm{C}$. 
It is known that fatty acids, interacting with proteins, can act as denaturing agents [23]. It is also known that the denaturing effect of fatty acids increases with the length of the hydrocarbon chain and the same effect was achieved with lower concentrations of fatty acids as their hydrophobicity increases. The degree of denaturation depends on the $\mathrm{pH}$ of the medium and the concentration of fatty acids. Because of this, we expected that fatty acids and lipids would act as inhibitors of acidic proteinases.

The effect of fatty acids and neutral lipids on the activity of acidic and neutral proteinases is shown in Fig. 2. From the data presented, it is clear that as the concentration of fatty acids increases, their inhibitory capacity also increases. At the same time, neutral proteinase is more inhibited by fatty acids (Fig. 2, curve 2 ) and acidic proteinase loses only about $10 \%$ of its original activity (Fig. 2, curve 1).

Neutral lipids do not significantly affect the activity of acidic and neutral proteinases (Fig. 2b). Reduction of acid proteinase activity in the presence of lipids at concentration of $8 \mathrm{mg} / \mathrm{mL}$ was $16-18 \%$ (Fig. 2, curve 1), and no decrease in the activity of neutral proteinase at this concentration was observed (Fig. 2, curve 2).

Fatty acid has not only an inactivating effect. In its

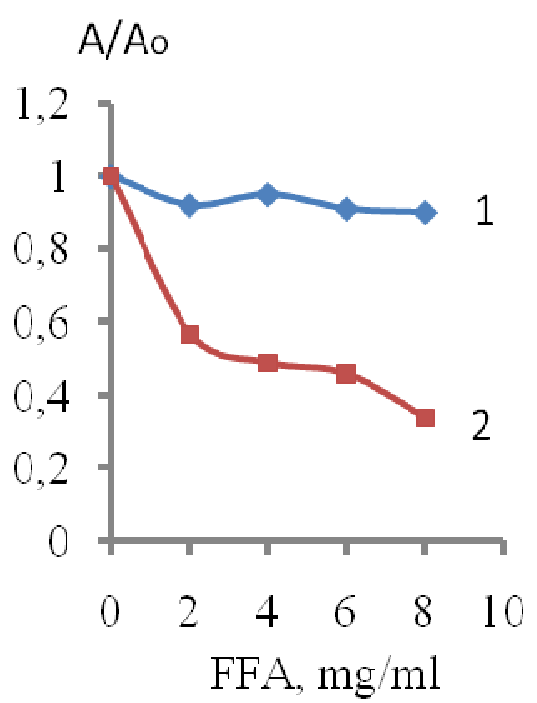

presence, the thermal stability of the studied proteinases was significantly reduced. From the data presented in Fig. 3 it can be seen that thermal stability of neutral proteinase was reduced. For example, after 20-25 min of incubation at $50{ }^{\circ} \mathrm{C}$ in the presence of 8 $\mathrm{mg} / \mathrm{mL}$ of fatty acid, neutral proteinase loses $90 \%$ of its original activity. During the same time, in the absence of fatty acid, the activity of the enzyme decreases only by $40-45 \%$. This effect depends not only on fatty acid, but also on the nature of proteinases. Thus, in the case of acidic proteinase at the same concentration of fatty acid, despite that the activity was slightly reduced $(10 \%)$, the destabilizing effect was not observed (Fig. 3, curves 1 and 2).

In Fig. 4 the dependence of hydrolysis rate on concentration of the substrate in the presence of linolenic acid in the coordinates of Lineweaver-Burke is presented. It can be seen that the value of the maximum achieved reaction rate decreases in the presence of a fatty acid (a segment on the ordinate axis). At the same time, the effective value of the apparent Michaelis constant increases (a segment on the abscissa axis). This suggests that fatty acid not only makes the enzyme more sensitive to thermal denaturation, but also, in a certain extent, reduces the affinity of acidic proteinase to its substrate.

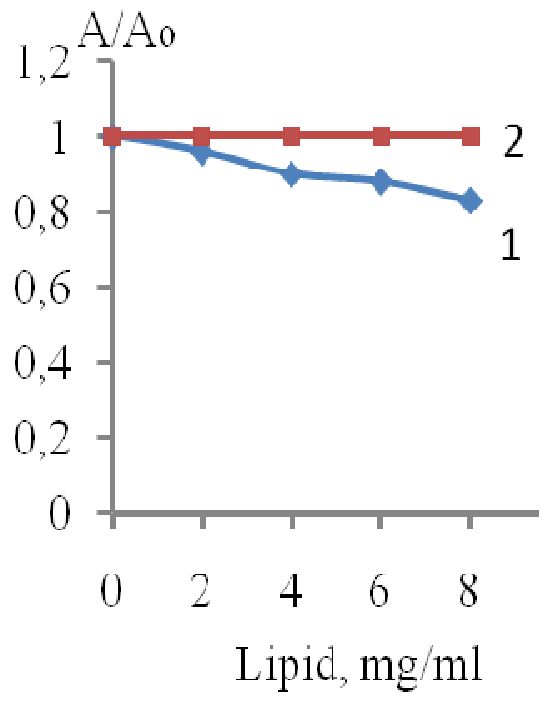

Fig. 2 The effect of linolenic acid (a) and cottonseed oil (b) on the activity of acid (1) and neutral (2) proteinases. 

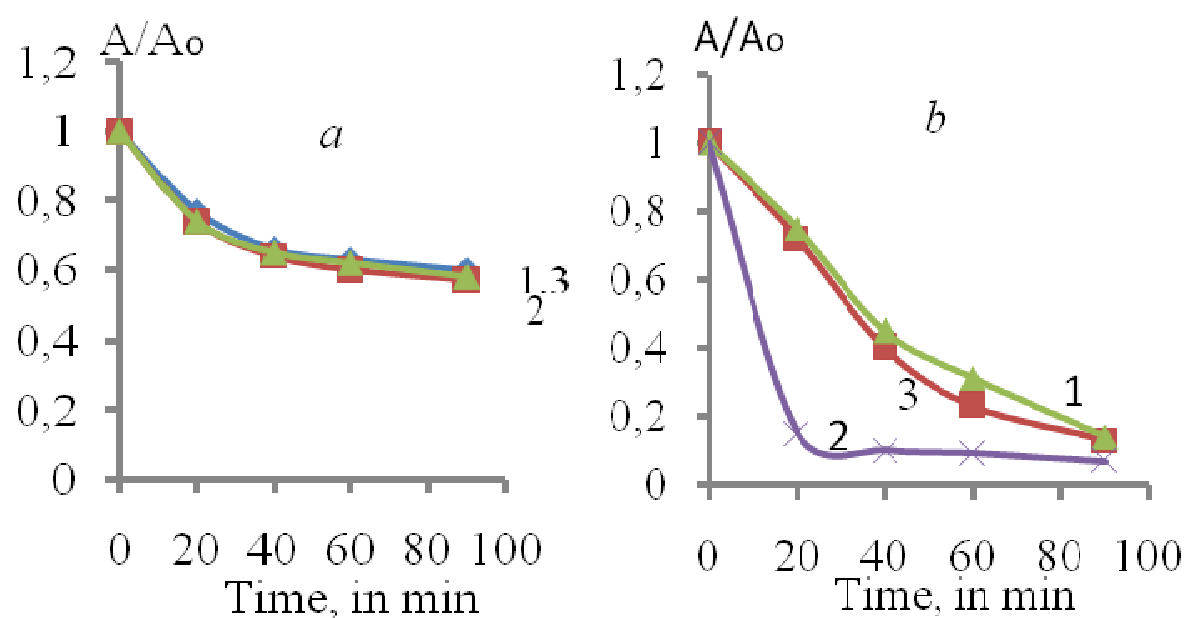

Fig. 3 The stability of acidic (a) and neutral (b) proteinases in various media. 1-control, 2-in the presence of linolenic acid, 3 -in the presence of cottonseed oil.

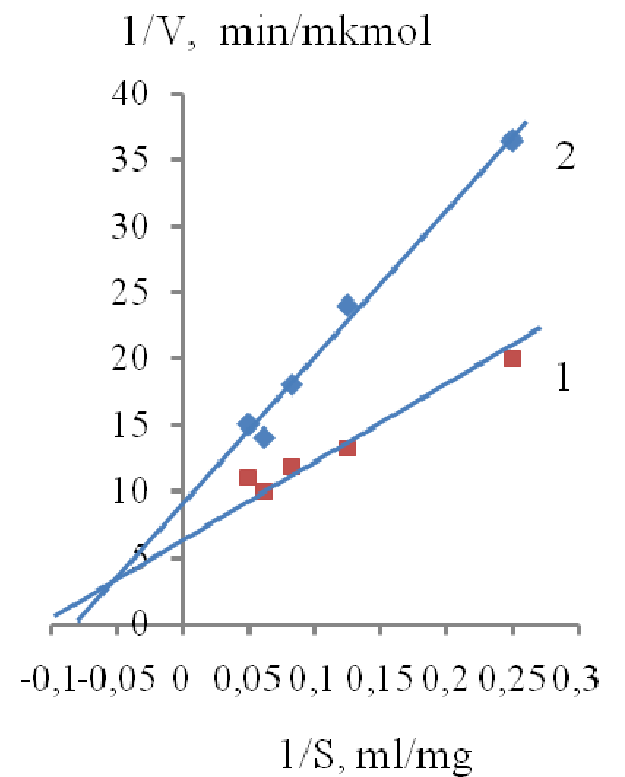

Fig. 4 The influence of a substrate concentration on the activity of neutral proteinases in the absence (1) and in the presence of linolenic acid (2) in the coordinates of Lineweaver and Burk.

\subsection{The Effect of Gossypol on the Activity and Stability of Proteinases}

Gossypol is a plant pigment found in cottonseed, both in free and bound state. In the cottonseed kernels, the content of gossypol is $0.66-1.44 \%$ [21].

Gossypol is a highly active chemical compound containing two aldehyde and six hydroxyl groups, two binaphthyl rings, and has the ability to tautomeric transformations [24]. Unique features of the structure and chemical properties of gossypol molecules allow it to form quite stable bonds with various proteins, and also easily integrate into phospholipid cytoplasmic membranes [25]. Due to such interactions, gossypol blocks the activity of a number of enzymes involved in various metabolic processes in plant cells, microorganisms and many other species of living beings.

When processing the cottonseed kernels with enzymes, because of the interaction with gossypol, the enzymatic process can proceed at a low rate.

Our research showed that gossypol significantly affects the catalytic properties of enzymes. At the same time, the type of enzyme used and the conditions for carrying out the process are important.

The effect of the concentration of gossypol on the activity of acidic and neutral proteinases is presented in Fig. 5.

From the data presented, it can be seen that acidic proteinase was less inhibited in the presence of gossypol in the reaction medium (Fig. 1, curve 2), whereas, neutral proteinase is more inhibited by gossypol (Fig. 1, curve 2). With a gossypol concentration in the reaction medium up to $2.5 \mathrm{mg} / \mathrm{mL}$, neutral proteinase loses up to $70 \%$ of the original activity.

In the presence of gossypol, the thermal stability of enzymes also changes. From the data presented in Fig. 
6 , it can be seen that thermal stability of neutral proteinase has reduced. Thus, for example, after 20 minutes of incubation at $50{ }^{\circ} \mathrm{C}$ in the presence of 1 $\mathrm{mg} / \mathrm{mL}$ of gossypol, the neutral proteinase loses $50 \%$ of its original activity. During the same time, in the absence of gossypol, the activity of the enzyme decreases only by $8-10 \%$. This effect depends not only on gossypol, but also on the nature of proteinases. So, in the case of acidic proteinase, with the same concentration of gossypol, although the activity was slightly reduced $(2 \%)$, the destabilizing effect was not observed (Fig. 6, curves 1 and 2).

The destabilizing effect of gossypol in neutral media can be explained by the formation of covalent bonds on the Schiff base between amino groups of the protein and the aldehyde groups of gossypol. Usually, this reaction occurs at alkaline $\mathrm{pH}$ values of the medium. The additional bonds of electrostatic nature (due to the ionized $\mathrm{OH}$ group), hydrophobic nature (due to the naphthalene ring and isopropyl groups) and the donor-acceptor type (due to $\pi$-electron-conjugated bonds) can also be formed [26]. In acidic media, because of the instability of the Schiff base, a covalent bond between the enzyme and gossypol was not formed. Therefore, in the case of acidic proteinases, there is no decrease in activity and thermal stability in the presence of gossypol.

Gossypol also affects kinetic constants of enzymatic reactions. Fig. 7 shows the dependence of a

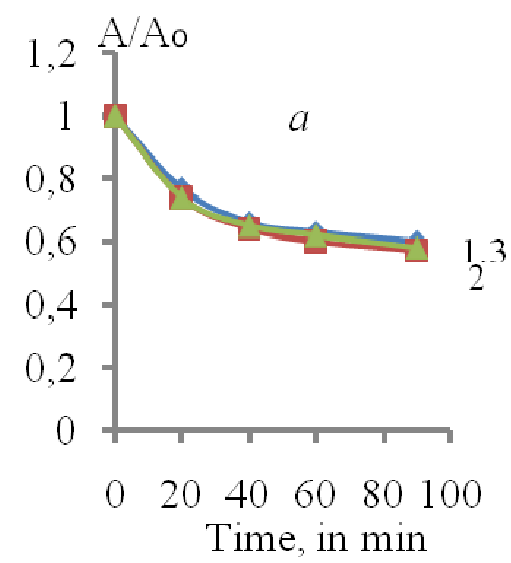

substrate hydrolysis rate on its concentration in the presence of gossypol in the coordinates of the Linuiver-Burke. It can be seen that the value of the maximum achieved reaction rate does not change in the presence of gossypol (a segment on the ordinate axis).

At the same time, the effective value of the apparent Michaelis constant increases (a segment on the abscissa axis). This suggests that gossypol not only makes the enzyme more sensitive to thermal denaturation, but also, in a certain extent, reduces the affinity of neutral proteinase to its substrate, and consequently, the enzyme's ability to carry out the catalytic stage of the hydrolysis process deteriorates.

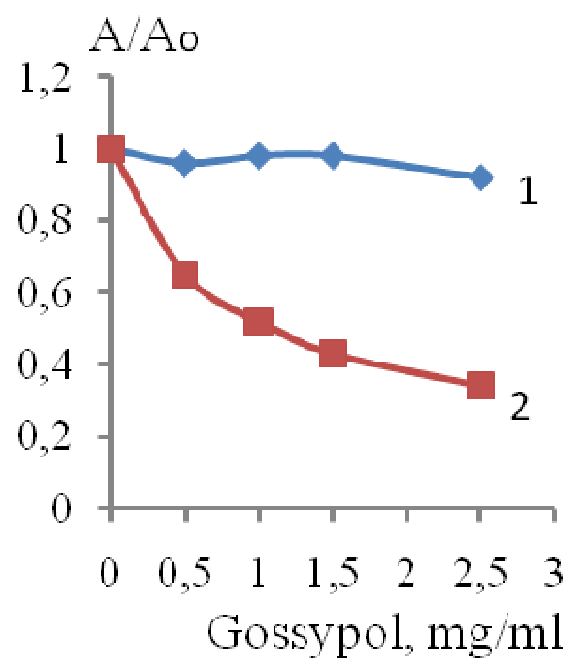

Fig. 5 The effect of gossypol concentration on the activity of acidic (1) and neutral (2) proteinases.

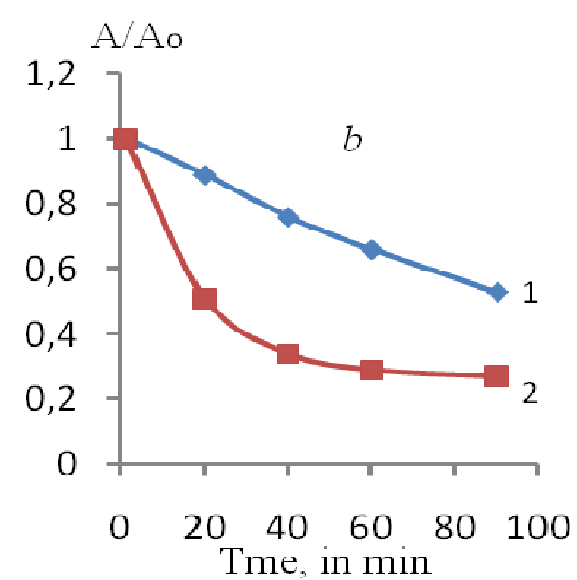

Fig. 6 The effect of gossypol on the stability of acidic (a) and neutral (b) proteinases. 1-without gossypol, 2-in the presence of gossypol. 


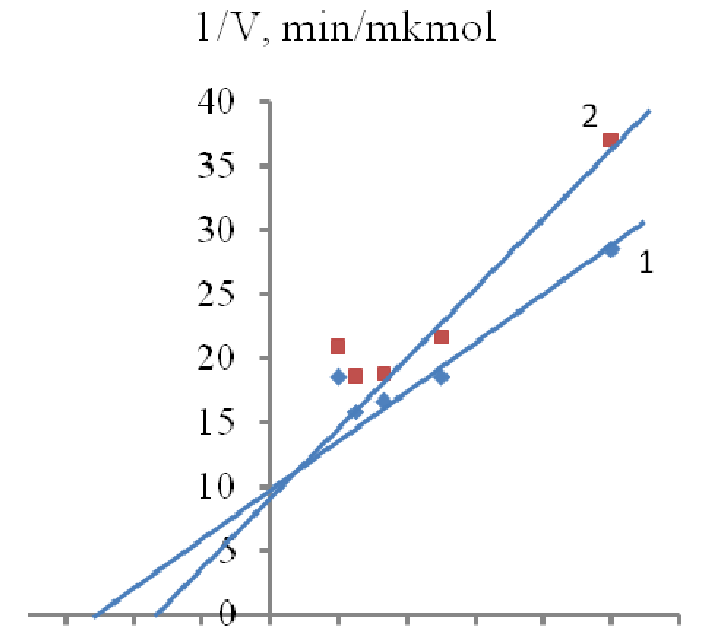

$-0,15-0,1-0,05 \quad 0 \quad 0,050,10,150,20,250,3$

\section{$1 / \mathrm{S}, \mathrm{ml} / \mathrm{mkmol}$}

Fig. 7 The influence of substrate concentration on the activity of neutral proteinases in the absence (1) and in the presence of gossypol (2) in the coordinates of Lineweaver and Burk.

\subsection{The Effect of Amylases and Proteinases on the} Extraction of Cottonseed Oil by Pressing

It is known that oil in the seeds is in the form of tubules or spheres [27]. The protein content in the core of cotton seed varies between $25-38 \%$. In this case, albumin and globulin account for $90 \%$ of the total number of proteins. The total content of carbohydrates is $12-14 \%$ [21].

During the frying of cotton seed kernel, structural changes occur in the components of the plant tissue, including tubules. In this case, the denaturation of the protein layer takes place, which contributes to the improvement of the extraction process of oil during pressing.

It should be noted that seeds of many plants contain natural inhibitors of proteinases and proteinase amylases [28], which under in situ conditions participate in the regulation of proteolytic and amylolytic enzymes activity. It also applies to cotton seeds [29]. Protein inhibitors lose their inhibitory ability during heat treatment. To reduce the inhibitory effect of the inhibitor, we studied the influence of preliminary heat treatment of the cotton seed kernels on the enzymatic processes with participation of exogenous enzymes for comparison.

Table 1 presents the results of the action of acidic and neutral proteinases action on proteins of the cottonseed kernels, pretreated at $95^{\circ} \mathrm{C}$.

From the data in Table 1, it can be seen that the preliminary heat treatment positively affects the hydrolysability of the cottonseed kernels proteins. At the same time, the formation of products of proteins hydrolysis increased by 1.7-2.0 times. Thus, for example, during fermentation of the cotton seed kernels for $60 \mathrm{~min}, 23.5 \pm 1.0 \mu \mathrm{mol} / \mathrm{g}$ of product is formed due to enzymatic hydrolysis against $11.7 \pm 0.5$ $\mu \mathrm{mol} / \mathrm{g}$ in the control.

The thermal treatment of the cottonseed kernels has slow effect on the hydrolysability of carbohydrates by amylolytic enzymes. In Table 2 the rate of formation of reducing sugars during the enzymatic treatment of cottonseed kernels is shown.

Table 1 Formation of hydrolysis products* of cottonseed protein by acidic and neutral proteinases.

\begin{tabular}{lllll}
\hline \multirow{2}{*}{ Time of hydrolysis, $\min$} & \multicolumn{3}{c}{ Cottonseed kernels } \\
\cline { 2 - 5 } & \multicolumn{2}{c}{ Without thermal processing } & \multicolumn{2}{c}{ With thermal processing } \\
\cline { 2 - 5 } & Acidic proteinase & Neutral proteinase & Acidi proteinase & Neutral proteinase \\
\hline 0 & 0 & 0 & 0 & 0 \\
30 & $2.5 \pm 0.12$ & $10.8 \pm 0.4$ & $1.2 \pm 0.04$ & $17.5 \pm 0.8$ \\
60 & $3.5 \pm 0.14$ & $11.7 \pm 0.5$ & $2.2 \pm 0.12$ & $23.5 \pm 1.0$ \\
90 & $4.2 \pm 0.19$ & $12.0 \pm 0.5$ & $3.0 \pm 0.12$ & $24.8 \pm 1.0$ \\
120 & $4.2 \pm 0.19$ & $12.0 \pm 0.5$ & $3.1 \pm 0.12$ & $26.3 \pm 1.0$ \\
\hline
\end{tabular}

\footnotetext{
* products of hydrolysis (amino acids) $\mu$ mol per $1 \mathrm{~g}$ of cottonseed kernels.
} 
Table 2 The formation of reducing sugars* at enzymatic hydrolysis of carbohydrates of cottonseed kernels.

\begin{tabular}{lll}
\hline \multirow{2}{*}{ Enzymes } & \multicolumn{2}{c}{ Cottonseed kernels } \\
\cline { 2 - 3 } & Without thermal processing & With thermal processing \\
\hline$\alpha$-amylase & $22.6 \pm 1.0$ & $12.8 \pm 0.5$ \\
$\alpha$-amylase and $\beta$-amylase & $34.6 \pm 1.3$ & $31.0 \pm 1.3$ \\
\hline
\end{tabular}

* in $\mathrm{mg}$ of sugar per $1 \mathrm{~g}$ of cottonseed kernels.

Table 3 The effect of fermentation on the oil extraction from cottonseed kernels.

\begin{tabular}{lll}
\hline Parameter & Without thermal processing & With thermal processing \\
\hline Oil content in the seeds, \% & $19.4 \pm 0.3$ & $19.4 \pm 0.3$ \\
Pressed oil yield, \% & $12.6 \pm 0.5$ & $13.5 \pm 0.5$ \\
Extracted oil yield, \% & $5.4 \pm 0.2$ & $4.5 \pm 0.2$ \\
\hline
\end{tabular}

From the data presented, it is clear that the formation of reducing sugars during fermentation of the cottonseed kernels with $\alpha$-amylase was $22.6 \pm 1.0$ $\mathrm{mg} / \mathrm{g}$. With the joint use of $\alpha$-amylase and $\beta$-amylase, the rate of carbohydrates hydrolysis was more intensive and the formation of reducing sugars was $34.6 \pm 1.3 \mathrm{mg} / \mathrm{g}$.

The formation of reducing sugars during fermentation of the heat-treated cottonseed kernels was $12.8 \pm 0.5 \mathrm{mg} / \mathrm{g}$ for $\alpha$-amylase and $31.0 \pm 1.3$ $\mathrm{mg} / \mathrm{g}$ at combined use of $\alpha$ - and $\beta$-amylases.

Thus, the moisture-heat treatment of the cottonseed kernels has a positive effect on enzymatic processes, increasing the degree of protein substances hydrolysis. In addition, the hydrolysis of carbohydrates with a slight decrease in the rate of hydrolysis also takes place.

Enzymatic treatment of the cottonseed kernels with amylases and proteinases before frying has a positive effect on the process of oil extraction. In Table 3 the effect of the enzymatic treatment of the cottonseed kernels on the yield of the resulting pre-press cottonseed oil is shown.

From the data of Table 3, it can be seen that the yield of pressed oil during fermentation of the cottonseed kernels grows up to $13.5 \pm 0.5 \%$. The yield of press oil without fermentation was $12.6 \pm 0.5 \%$. Due to this, the yield of extracted oil decreases.

\section{Conclusion}

When processing cotton seeds, the proteolytic enzymes can undergo inactivation, due to the inhibitory effect of lipids, fatty acids and gossypol. At the same time, the acid proteinase from the fungus Aspergillus niger was more resistant to fatty acids, as compared with neutral proteinase from bacterium Bacillus amyloliquefaciens.

Moisture-heat treatment of the cotton seed kernels positively affects the enzymatic processes, increasing the degree of hydrolysis of proteinaceous substances and also affects the prepress extraction of oil, increasing its yield. These data can be used to improve the process of oil extraction from oil seeds.

\section{References}

[1] Latif, S., Anwar, F., and Ashraf, M. 2007. "Characterization of Enzyme-Assisted Cottonseed Oil by Cold Pressing." J Food Lipid 14 (4): 424-36.

[2] Soto, C. G., Chamy, R., and Zuniga, M. 2004. "Effect of Enzymatic Application on Borage (Borago officinalis) Oil Extraction by Cold Pressing." J Chem Eng Japan 37 (3): $326-31$

[3] Bezborodov, A. M., and Zagustina, N. A. 2014. "Lipases in Catalytic Reactions of Organic Chemistry." Applied Biochemistry and Microbiology 50 (4): 313-37.

[4] Neklyudov, A. D., and Ivankin, A. N. 2002. "Biochemical Processing of Fats and Oils as a Means of Obtaining Lipid Products with Improved Biological and Physicochemical Properties: A Review." Applied Biochemistry and Microbiology 38 (5): 399-409..

[5] Davidova, E. M., and Petrovichev, V. A. 2002. "Practical Experience Using Enzyme Technology." Maslojirovaya Promishlennost 3: 24-25.

[6] Turner, C., Wani, S., Wong, K., Lin, J.-T., and McKeon, T. 2006. "Lipase-Catalyzed Esterification of 2-Monoricinolein for 1,2(2,3)-Diricinolein Synthesis." 
Lipids 41 (1): 77-83.

[7] Rosenthal, A., Pyle, D. L., and Niranjan, K. 1996. "Aqueous and Enzymatic Processes for Edible Oil Extraction.” Enzym Microb Technol. 19: 402-20.

[8] Rosenthal, A., Pyle, D. L., Niranjan, K., Gilmour, S., and Trinca, L. 2001. "Combined Effect of Operational Variables and Enzyme Activity on Aqueous Enzymatic Extraction of Oil and Protein From Soybean.” Enzym Microb Technol. 28: 499-509.

[9] Lamsal, B., Murphy, P., and Johnson, L. 2006. "Flaking and Extrusion as Mechanical Treatments for Enzyme-Assisted Aqueous Extraction of Oil from Soybeans." J Am Oil Chem Soc. 83: 973-9.

[10] Sineiro, J., Dominguez, H., Nunez, M. J., and Lema, J. M. 1998. "Optimization of the Enzymatic Treatment during Aqueous Oil Extraction from Sunflower Seeds." Food Chem. 61: 467-74.

[11] Hanmoungjai, P., Pyle, D. L., and Niranjan, K. 2002. "Enzyme-Assisted Water-Extraction of Oil and Protein from Rice Bran.” J Chem Technol Biotechnol. 77: 771-6.

[12] Bocevska, M., Karlovic, D., Turkulov, J., and Pericin, D. 1993. "Quality of Corn Germ Oil Obtained by Aqueous Enzymatic Extraction." J Am Oil Chem Soc. 70: 1273-7.

[13] Moreau, R., Johnston, D., Powell, M., and Hicks, K. 2004. "A Comparison of Commercial Enzymes for the Aqueous Enzymatic Extraction of Corn Oil from Corn Germ." $J$ Am Oil Chem Soc. 81: 1071-5.

[14] Zhang, S., Wang, Z., and Xu, S. 2007. "Optimization of the Aqueous Enzymatic Extraction of Rapeseed Oil and Protein Hydrolysates." J Am Oil Chem Soc. 84: 97-105.

[15] Barrios, V. A., Olmos, D. A., Noyola, R. A., and Lopez-Munguia, C. A. 1990. "Optimization of an Enzymatic Process for Coconut Oil Extraction.” Oleagineux. 45: 35-42.

[16] Lusas, E. W., Lawhon, J. T., and Rhee, K. C. 1982. "Producing Edible Oil and Protein from Oilseeds by Aqueous Processing." Oil Mill Gazet. 4: 28-34.

[17] Sosulski, K., and Sosulski, F. W. 1993. "Enzyme-Aided vs. Two-Stage Processing of Canola: Technology, Product Quality and Cost Evaluation.” J Am Oil Chem Soc. 70: 825-9.

[18] Dominguez, H., Nunez, M. J., and Lema, J. M. 1993. “Oil Extractability from Enzymatically Treated Soybean and Sunflower: Range of Operational Variables." Food Chemistry 46: 277-84.

[19] Sosulski, K., Sosulsky, F. W., and Coxworth, E. 1988. "Carbohydrate Hydrolysis of Canola to Enhance Oil Extraction with Hexane." J Am Oil Chem Soc. 65: 357-61.

[20] Enzyme Preparations. 1985. Method of Determining Proteolytic Activity. Moscow, GOST 20264.2-85.

[21] Sergeeva, A. G., ed. 1974. Manual on the Technology of Production and Processing of Vegetable Oils and Fats. VNIIZh, p. 580.

[22] Sinicin, A. P., Chernoglazov, V. M., and Gusakov, A. V. 1990. "Methods of Study and Properties of Cellulolytic Enzymes." Results of Science and Technology. Ser. "Biotechnology". VINIITI. M. 25: 30-7.

[23] Bull, M. B., and Breese, K. 1967. "Denaturation of Proteins by Fatty Acid." Archiv. Biochem. Biophys. 120: 303-15.

[24] Kenar, J. A. 2006. "Reaction Chemistry of Gossypol and Its Derivatives." J Am Oil Chem Soc. 83 (4): 269-302.

[25] Strom-Hansen, T., Cornett, C., and Jaroszewski, J. W. 1989. "Interaction of Gossypol with Amino Acids and Peptides as a Model of Enzyme Inhibition." International Journal of Peptide and Protein Research 34 (4): 306-10.

[26] Kenar, J. A. 2006. "Reaction Chemistry of Gossypol and Its Derivatives.” J Am Oil Chem Soc. 83 (4): 269-302.

[27] Goldovskiy, A. M. 1958. "Theoretical Basis for the Production of Vegetable Oils.” M. Pishepromizdat. 432.

[28] Mosolov, V. V., and Valueva, T. A. 2005. "Proteinase Inhibitors and Their Function In Plants: A Review." Applied Biochemistry and Microbiology 41 (3): 227-46.

[29] Kasymova, T. D., and Yuldashev, P. K. 1995. "Isolation and Characterization of Protease Inhibitors from Cotton Seeds." Chemistry of Natural Compounds 3: 369-71. 